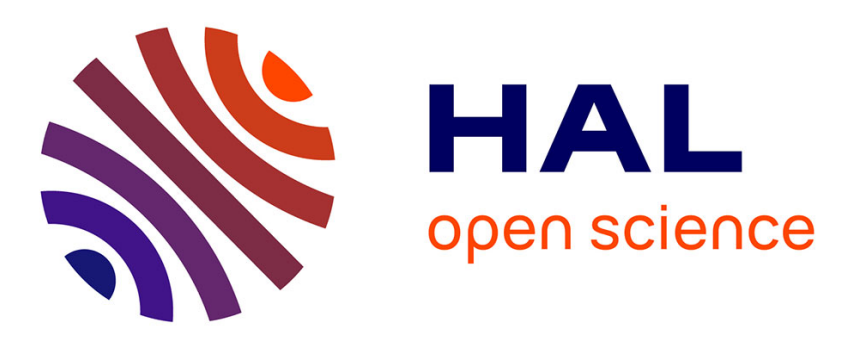

\title{
Investigation of Defects and Atomic Ordering in Fe72A128 by Positron Annihilation and Mössbauer Spectroscopy
}

Y. Jiraskova, O. Schneeweiss, M. Sob, I. Novotny, I. Prochazka, F. Becvar, B. Sedlak, F. Sebesta, M. Puska

\section{To cite this version:}

Y. Jiraskova, O. Schneeweiss, M. Sob, I. Novotny, I. Prochazka, et al.. Investigation of Defects and Atomic Ordering in Fe72Al28 by Positron Annihilation and Mössbauer Spectroscopy. Journal de Physique IV Proceedings, 1995, 05 (C1), pp.C1-157-C1-161. 10.1051/jp4:1995118 . jpa-00253554

\section{HAL Id: jpa-00253554 https://hal.science/jpa-00253554}

Submitted on 1 Jan 1995

HAL is a multi-disciplinary open access archive for the deposit and dissemination of scientific research documents, whether they are published or not. The documents may come from teaching and research institutions in France or abroad, or from public or private research centers.
L'archive ouverte pluridisciplinaire HAL, est destinée au dépôt et à la diffusion de documents scientifiques de niveau recherche, publiés ou non, émanant des établissements d'enseignement et de recherche français ou étrangers, des laboratoires publics ou privés. 


\title{
Investigation of Defects and Atomic Ordering in $\mathrm{Fe}_{72} \mathbf{A l}_{28}$ by Positron Annihilation and Mössbauer Spectroscopy
}

\author{
Y. Jirásková, O. Schneeweiss, M. Šob, I. Novotný*, I. Procházka*, F. Bečváá*, B. Sedlák*, \\ F. Sebesta** and M.J. Puska*** \\ Institute of Physics of Materials, Academy of Sciences of the Czech Republic, Żižkova 22, \\ CZ-616 62 Brno, Czech Republic \\ * Department of Low-Temperature Physics, Charles University, V Holešovičkách 2, CZ-180 00 Praha 8 , \\ Czech Republic \\ ** Faculty of Nuclear Sciences and Physical Engineering, Czech Technical University, Břehová 7, \\ CZ-115 19 Praha, Czech Republic \\ *** Laboratory of Physics, Helsinki University of Technology, SF-02150 Espoo, Finland
}

\begin{abstract}
Iron aluminide $\mathrm{Fe}_{72} \mathrm{Al}_{28}$ was investigated in states with different defect concentrations using the positron annihilation lifetime and Mössbauer spectroscopy methods. The dominant component of $178-187 \mathrm{ps}$, obtained from positron lifetime spectra analysis, corresponds to a high density of vacancies. In the sample where high concentrations of vacancies or dislocations and vacancy clusters were found simultaneously, a second component with a lifetime of 335 ps appears. Mössbauer results show that in the alloy above the $\mathrm{Fe}_{3} \mathrm{Al}$ stoichiometry concentration the vacancies prefer to occupy the sublattice in the $\mathrm{DO}_{3}$ superstructure which is reserved for both iron and aluminium atoms. However, this conclusion could not be verified by comparison of theoretical and experimental values of positron lifetimes as the theoretically predicted positron lifetimes for all three types of vacancies are nearly the same.
\end{abstract}

\section{INTRODUCTION}

Mechanical and magnetic properties of intermetallics depend on atomic ordering and content of defects, often influenced by heat and/or mechanical treatments. Recently, the alloy $\mathrm{Fe}_{72} \mathrm{Al}_{28}$ prepared by rapid quenching from the melt and deformed by rolling at room temperature $(58 \%$ plastic deformation) was investigated [1]. Analysis of Mössbauer spectra has revealed that a high dislocation density volume occupied a dominant part of the strained samples (up to $74 \%$ ). This was confirmed also by positron lifetime measurements showing a large component with intensity of $89 \%$ and lifetime of about 162 ps. This value was close to positron lifetime of 167 ps attributed to the positron annihilation in dislocations in plastically deformed iron [2].

In the present work, the same alloy prepared by a conventional method with different heat treatments was investigated. Changes in atomic ordering, the type of defects and their concentration as well as the site preference of vacancies in the $\mathrm{DO}_{3}$ superstructure, characteristic for this alloy, were studied.

\section{EXPERIMENTAL}

The ingot of the Fe-28 at.\% Al alloy was prepared from pure iron and aluminium (of purity 
better than 0.999) by induction melting in Ar. Its chemical composition was confirmed by EDX microanalysis. For the positron lifetime measurements a similar type source-sample arrangement as in [3] was used. A cylindrical sample $5 \mathrm{~mm}$ in diameter and $12 \mathrm{~mm}$ in length was prepared from two pieces with ${ }^{22} \mathrm{Na}$ activity of about $5 \mu \mathrm{Ci}$ deposited on the contact spot between them. Both parts were then welded together with the aid of an electron beam (Fig. 1). The lifetime spectra were measured using a fast-slow coincidence spectrometer with $\mathrm{BaF}_{2}$ scintillators, the experimental time resolution being $150 \mathrm{ps}$. The spectra were decomposed into three lifetime components. The third component had an intensity less than $1 \%$ and was not considered in the physical interpretation of the results. For Mössbauer spectroscopy foils of about $35 \mu \mathrm{m}$ thickness were used. Spectra were taken in the transmission geometry at room temperature using ${ }^{57} \mathrm{Co}$ in a $\mathrm{Cr}$ source. The velocity scale was calibrated against $\alpha$-iron. Spectra were processed using a least-squares analysis by assuming a combination of discrete components and continuous hyperfine induction distribution based on a fast Fourier transform convolution procedure [4].

The following states of the alloy were investigated:

Sample S1: as-prepared cast and machined ingot;

Sample S2: obtained by annealing of sample S1 at $1123 \mathrm{~K}$ for 2 hours in vacuum and slow cooling down to ambient temperature;

Sample S3: sample S2 after quenching $(100 \mathrm{~K} / \mathrm{s})$ in vacuum from $1273 \mathrm{~K}$;

Sample S4: sample S3 after recovery annealing at $443 \mathrm{~K}$ for 140 hours in $\mathrm{Ar}+\mathrm{H}_{2}$.

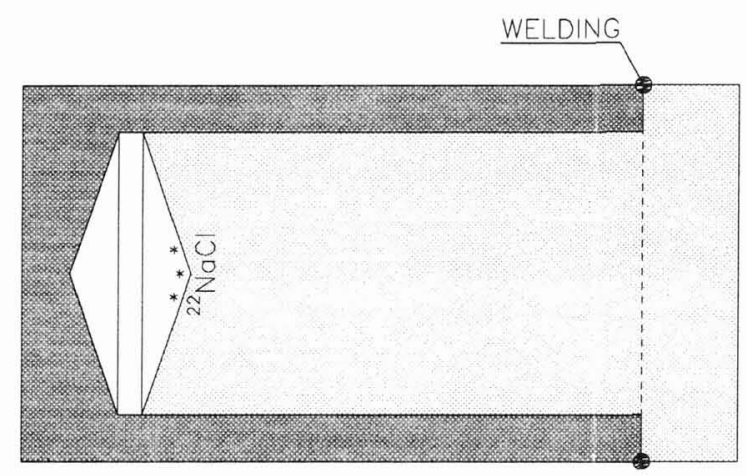

Figure 1. Section of the positron lifetime source-sample arrangement.

\section{RESULTS AND DISCUSSION}

The parameters of the positron lifetime (LT) spectra are given in table 1. Values of the mean hyperfine induction derived from the Mössbauer spectra are summarized in table 3.

Table 1. Lifetime constants $\tau$ and intensities I derived from the positron lifetime spectra.

\begin{tabular}{|c|c|c|c|c|c|c|}
\hline Sample No. & $\begin{array}{c}\tau_{1} \\
{[\mathrm{ps}]}\end{array}$ & $\begin{array}{c}\mathrm{I}_{1} \\
{[\%]}\end{array}$ & $\begin{array}{c}\tau_{2} \\
{[\mathrm{ps}]}\end{array}$ & $\begin{array}{c}\mathrm{I}_{2} \\
{[\%]}\end{array}$ & $\begin{array}{c}\tau_{3} \\
{[\mathrm{ps}]}\end{array}$ & $\begin{array}{c}\mathrm{I}_{3} \\
{[\%]}\end{array}$ \\
\hline $\mathrm{S} 1$ & - & - & $178 \pm 2$ & $92 \pm 2$ & $335 \pm 23$ & $8 \pm 2$ \\
\hline $\mathrm{S} 2$ & $94 \pm 2$ & $59 \pm 2$ & $184 \pm 3$ & $41 \pm 2$ & - & - \\
\hline $\mathrm{S} 3$ & $43 \pm 5$ & $14 \pm 1$ & $184 \pm 1$ & $86 \pm 1$ & - & - \\
\hline $\mathrm{S} 4$ & $65 \pm 4$ & $12 \pm 1$ & $187 \pm 1$ & $88 \pm 1$ & - & - \\
\hline
\end{tabular}


It is known that the aluminide studied exhibits the $\mathrm{DO}_{3}$ superstructure [5], and the present Mössbauer spectra confirmed a high degree of this atomic order in all samples investigated. The $\mathrm{D0}_{3}$ superstructure can be divided into four sublattices labelled A, B, C, and D (Fig. 2). In the fully ordered state, the sites $\mathrm{A}$ and $\mathrm{C}$ are occupied by Fe atoms. The sublattice $\mathrm{B}$ is shared by Fe and overstoichiometric ( $>25$ at. \%) Al atoms, whereas the sublattice D is occupied by Al atoms. The analysis of the positron LT spectra reveals a dominant component $\tau_{2}$ of $178-187 \mathrm{ps}$ in the samples S1, S3 and S4. Also the ordered sample S2 exhibits a component of 184 ps with an appreciable intensity.

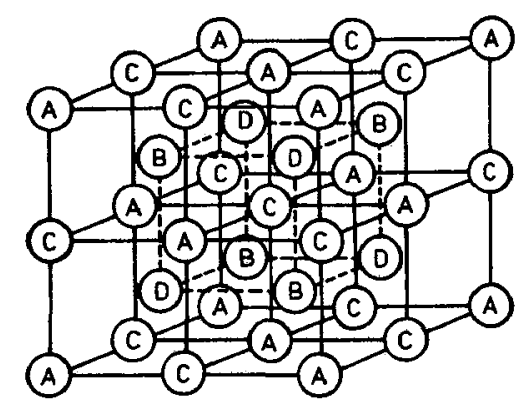

Figure 2. $\mathrm{DO}_{3}$ superlattice.

Theoretical calculations by the superimposed atom method [6] yield a lifetime of 186 ps for $\mathrm{Fe}$ vacancies on $A$ and $C$ sublattices as well as on the $B$ sublattice and of 184 ps for $A l$ vacancies on the D sublattice (see Table 2). These values agree very well with the lifetime component discussed above; however, as they are nearly identical, they do not allow us to distinguish at which vacancies the annihilation of positrons dominates.

Table 2. Results of theoretical calculations of the lifetime for vacancies on different sites of the $\mathrm{D0}_{3}$ superlattice (superimposed atom method). The abbreviation nn means nearest neighbour.

\begin{tabular}{|c|c|c|c|c|}
\hline Site & Regular atoms & 1st $\mathrm{nn}$ & 2nd nn & Lifetime [ps] \\
\hline $\mathrm{A}, \mathrm{C}$ & $\mathrm{Fe}$ & $4 \mathrm{Fe}+4 \mathrm{Al}$ & $6 \mathrm{Fe}$ & 186.4 \\
$\mathrm{~B}$ & $\mathrm{Fe}, \mathrm{Al}$ & $8 \mathrm{Fe}$ & $6 \mathrm{Al}$ & 186.0 \\
$\mathrm{D}$ & $\mathrm{Al}$ & $8 \mathrm{Fe}$ & $6 \mathrm{Fe}$ & 184.0 \\
\hline
\end{tabular}

(Positron lifetime in perfect $\mathrm{Fe}_{3} \mathrm{Al}$ : 112 ps - theory, $112 \pm 2$ ps - experiment [3].)

Another component with a lifetime of $335 \mathrm{ps}$ was found in sample S1 and was assigned to the vacancy and vacancy-dislocation clusters. The intensity of this component is very low and vanishes after ordering annealing (sample S2). Its absence in sample S3 is due to the method of preparation as the quenching from a high temperature largely prevents the formation of vacancy-type defects. The other component in sample S2 with a lifetime of 94 ps corresponds to the decay of untrapped positrons. The value of the bulk positron lifetime $\tau_{\boldsymbol{B}}=118 \mathrm{ps}$, calculated according to the onedefect trapping model [7], does not show a significant difference from the calculated value of $112 \mathrm{ps}$ in the ordered $\mathrm{Fe}_{3} \mathrm{Al}$ compound, which was also confirmed experimentally [3]. This suggests that only one type of positron trap exists in this sample. Using the above bulk lifetime of 118 ps also for the samples S3 and S4, we have calculated the shorter lifetime component $\tau_{1, \text { test }}$ which would follow from the one-defect trapping model [7]. The value of $\tau_{1, \text { test }}=35 \mathrm{ps}$ in sample S3 does not deviate too much from the $\tau_{1}=43 \pm 5 \mathrm{ps}$ obtained from the decomposition and, therefore, the one-defect 
trapping model applies here, too. It seems that with our resolution of $150 \mathrm{ps}$ it is possible to catch even such short-lived components. In sample $\mathrm{S} 4$ we get $\tau_{1, t e s t}=25 \mathrm{ps}$, substantially different from the $\tau_{1}=64 \pm 4 \mathrm{ps}$ found from the fit. Here the following alternatives may be considered:

1. The one-defect trapping model does apply, but in the decomposition of the spectra it is not possible to resolve the short component from the peak.

2. There are more than one type of defects, e.g. shallow traps with a lifetime close to the bulk lifetime (antiphase boundaries or other defects, the electron density of which is only slightly lower than the electron density in the bulk). In this case the value of $\tau_{1}$ would increase.

At present, we are not able to decide which of these alternatives takes place. Further investigations in this direction are planned.

Table 3. Mean hyperfine induction $\mathrm{B}_{h f}$ of the samples derived from Mössbauer spectra.

\begin{tabular}{|c|c|c|c|c|}
\hline Specimen & S1 & S2 & S3 & S4 \\
\hline $\mathrm{B}_{h f}[\mathrm{~T}]$ & $8.3 \pm 0.1$ & $9.7 \pm 0.1$ & $4.9 \pm 0.1$ & $5.0 \pm 0.1$ \\
\hline
\end{tabular}

The main differences between the samples which can be derived from the Mössbauer spectra are reflected in the behaviour of the mean hyperfine induction $\mathrm{B}_{h f}$. They are due to changes in atomic arrangement of the nearest neighbours (nn) of the resonating iron atoms [8,9]. This arrangement is altered by atomic ordering and by the presence of vacancies. The influence of a vacancy among the $n n$ of an iron atom on its $B_{h f}$ can be roughly compared with the influence of an aluminium atom [10]. Therefore, the effect on $\mathrm{B}_{h f}$ of a high concentration of vacancies should be similar to that of an increase in $\mathrm{Al}$ concentration. Namely, in a perfectly ordered stoichiometric $\mathrm{DO}_{3}$ superstructure, the iron atoms on the $A$ and $C$ sublattices ( $F e^{A C}$ ) have four $\mathrm{Al}$ atoms from the $\mathrm{D}\left(\mathrm{Al}^{D}\right)$ and four $\mathrm{Fe}$ atoms from the $\mathrm{B}\left(\mathrm{Fe}^{B}\right)$ sublattice as nn. The presence of $\mathrm{Al}$ atoms in the sublattice $\mathrm{B}$ in $\mathrm{Fe}-\mathrm{Al}$ alloys with $\mathrm{Al}$ content larger than 25 at.\%, i.e. formation of $\mathrm{Fe} \mathrm{e}^{A C}$ atoms with $5 \mathrm{Al}$ atoms among the $\mathrm{nn}$, results in an important drop of $\mathrm{B}_{h f}$ and of the mean magnetic moment on the iron atoms [11,12]. A similar effect can be expected when $\mathrm{Fe}^{A C}$ with $4 \mathrm{Al}$ atoms and an iron vacancy among the $\mathrm{nn}$ is formed. According to the heat treatment and the LT results a relatively high concentration of vacancies is present in the samples S3 and S4. The occupation of $\mathrm{Al}^{D}$ sites by vacancies does not change the magnetic moment and the $\mathrm{B}_{h f}$ of the $\mathrm{Fe}^{A C}$ essentially, so that the effect of this can be excluded. Further, a vacancy on an $\mathrm{Fe}^{A C}$ site would produce an $\mathrm{Fe}^{B}$ atom having $7 \mathrm{Fe}^{A C}$ atoms and an iron vacancy as $\mathrm{nn}$. A decrease in $\mathrm{B}_{h f}$ due to this type of $\mathrm{nn}$ arrangement is much smaller than that found when a vacancy is placed on a $\mathrm{Fe}^{B}$ site and cannot account for the small values of $B_{h f}$ observed. This model could explain the simple case when the sample is characterized by a low density of dislocations. Plastic deformation changes the atomic ordering in the direction of $\mathrm{B} 2$ and $\mathrm{A} 2$ superstructures $[12,13]$. These changes in atomic arrangement can be connected with an increase in $\mathrm{B}_{h f}$ and in the mean magnetic moment [12-14]. This means that a decrease in $\mathrm{B}_{h f}$ due to increased vacancy concentration can be overshadowed by a stronger increase in $\mathbf{B}_{h f}$ due to variation in atomic ordering. In this way we can understand the important difference in $\mathrm{B}_{h f}$ in the $\mathrm{S} 1$ and $\mathrm{S} 3$ samples in spite of only slight differences in vacancy concentration according to the $L T$ results. In contrast with the recently observed recovery and partial vacancy annihilation already at $443 \mathrm{~K}$ in highly-strained samples [14], there are no changes in vacancy concentration and in $\mathrm{B}_{h f}$ between the $\mathrm{S} 3$ and $\mathrm{S} 4$ samples, in agreement with the LT results. This suggests that the annihilation of vacancies is connected with atomic ordering and rebuilding of the $\mathrm{D0}_{3}$ superstructure occurring above its critical temperature of $823 \mathrm{~K}$ [5]. In highly-strained samples annihilation of vacancies is probably accelerated by the presence of internal stresses and dislocation walls which can accept large amounts of diffusing vacancies. 


\section{CONCLUSIONS}

The LT spectra of the ordered and highly disordered $\mathrm{Fe}_{72} \mathrm{Al}_{28}$ alloy exhibit a lifetime component between 178-185 ps which was, in agreement with theoretical calculations, attributed to vacancies. As the theory predicts nearly the same lifetime for all three kinds of possible vacancies, we were not able to decide which type of vacancy dominates. However, the Mössbauer spectroscopy proved that vacancies prefer to occupy the $B$ sublattice in the $\mathrm{DO}_{3}$ superstructure which is common to both iron and aluminium atoms in overstoichiometric $\mathrm{Fe}-\mathrm{Al}$ alloys. If the number of vacancies or dislocations is high and vacancy clusters are formed, a second LT component of $335 \mathrm{ps}$ is observed. In the samples with the ordered $\mathrm{DO}_{3}$ superstructure and after quenching from $1273 \mathrm{~K}$, good agreement with the one-defect trapping model was found It turned out that at the resolution of $150 \mathrm{ps}$ even components as slow as 40 ps could be analyzed.

The recovery annealing does not change the Mössbauer parameters substantially. However, a disagreement between the one-defect trapping model and the fitted lifetime components is found. This may either be due to the inability of the lifetime analysis to resolve extremely short lifetime components (about $25 \mathrm{ps)}$ ) or by the presence of shallow traps in the sample, the electron density of which is only slightly lower than the electron density in the bulk, e.g. antiphase boundaries. The vacancies produced by quenching from high temperature are connected with atomic ordering and their annihilation at $443 \mathrm{~K}$ is probably very slow. However, the presence of internal stresses and dislocation walls can accelerate their disappearance also at lower temperatures.

This work was supported by the Research Grant No. 106/94/310 of the Grant Agency of the Czech Republic.

\section{References}

[1] Jirásková Y., Schneeweiss O. and Baranowski A., Key Engineering Materials 81-83 (1993) 203-208.

[2] Schaefer H.-E., Würschum R., Birringer R. and Gleiter H., Phys. Rev, B 38 (1988) 9545-9554.

[3] Schaefer H.-E., Wiurschum R., Šob M., Z̆ák T., Yu W.Z., Eckert W. and Banhart F., Phys. Rev. B 41 (1990) 11869-11874.

[4] Veselý V., Nucl. Instr. Meth. Phys. Res. B 18 (1986) 88-100.

[5] Inden G., Bull. Alloy Phase Diagrams 2 (1982) 412-413.

[6] Puska M. J. and Nieminen R. M., J. Phys. F: Metal Phys. 13 (1983) 333.

[7] Hautojärvi P. and Corbel C., in Positron Spectroscopy of Solids, Proceedings of the International School of Physics "Enrico Fermi", Course CXXV, A. Dupasquier and A. P. Mills, Jr., eds. (North Holland, Amsterdam, 1994), to be published.

[8] Schwartz L. H., in: Applications of Mössbauer Spectroscopy, ed. R. L. Cohen, vol.1, (Academic Press, New York, 1976) pp. 66-78.

[9] Schneeweiss O. and Žák T., J. Magn. Magn. Mater. 60 (1986) 265-269.

[10] Van der Woude F. and Sawatzky G. A., Physics Reports 12C (1974) 336-374.

[11] Okamoto H. and Beck P. A., Monatsh. Chemie 103 (1972) 907-921; Shull R. D., Okamoto H. and Beck P. A., Solid State Commun. 20 (1976) 863-868.

[12] Huffman G. P. and Fisher R. M., J. Appl. Phys. 38 (1967) 735-742; Huffman G. P., in: Amorphous Magnetism (Proc. Int. Symp., Detroit, 1972), eds. Hooper H. O. and de Graaf A. M. (Plenum Press, New York, 1973) pp, 283-290.

[13] Chin G. Y., in: Advances in Materials Research, vol.5, ed. H. Herman, (Wiley, New York, 1971) pp. 217-252.

[14] Jirásková Y., Kočová M., Pizúrová N., Z̆ák T. and Schneeweiss O., Mater. Sci. Technology 9 (1993) 397-402. 